\title{
Mediation Effects of Political Skills Dimensions on Employee Performance
}

\author{
Naveed Iqbal Chaudhry ${ }^{1,2}$, Kashif-ur-Rehman ${ }^{3}$, Zeeshan Ashraf $^{3} \&$ Abuzar Mehdi Jaffri ${ }^{3}$ \\ ${ }^{1}$ Business School, University of Bedfordshire, Luton, UK \\ ${ }^{2}$ Department of Commerce, University of the Punjab, Gujranwala, Pakistan \\ ${ }^{3}$ Department of Management Science, Iqra University, Islamabad, Pakistan \\ Correspondence: Naveed Iqbal Chaudhry, Business School, University of Bedfordshire, Luton, UK \& Department \\ of Commerce, University of the Punjab, Gujranwala, Pakistan. E-mail: naveediqbal81@yahoo.com
}

\author{
Received: April 26, 2011 \\ Accepted: March 15, 2012 \\ Published: May 1, 2012 \\ doi:10.5539/ijbm.v7n9p120 \\ URL: http://dx.doi.org/10.5539/ijbm.v7n9p120
}

\begin{abstract}
The main objective to conduct this research is to examine that how employee performance could be increase by the impact of different dimensions of political skills. To examine how employee performance can be affected by mediation relationship of four different dimensions of political skills if those dimensions directly related with proactive personality. The finding shows positive significant relation between proactive personality and employee performance having dimensions of political skills as mediator as mediator which then enhance employee performance. These findings could be used in big organizations to achieve significant results by developing the abilities of politics in employee which will further lead to greater employee performance.
\end{abstract}

Keywords: altruism, proactive personality, political skills, networking ability, in role performance

\section{Introduction}

Persons with high proactive personality they thinks to be more energetic towards taking initial steps to have an impact on their surrounding environment, they learn to dig out how to take benefit from their prevailing scrum stances and they make such type of circumstances to increase the social relation as compare to individuals having less proactive personality traits. Proactive personality and step taking behavior of employees plays an important part in the organization, reasonable research highlights the proactive approach in personality leave a great effect with respect to the performed actions and their results as mentioned by Crant (2000).

Researcher have focused and find out that proactive personality has good impact with reference to different types of organizational outputs, it also includes leading abilities leadership discussed by (Crant, 2000). Many researchers has shown the proactive approach in personality relate positively to many types of consequences within the organization simply one can assume that proactive persons can perform better. Some researcher has originates that job performance has a great impact on the success of their future mentioned by (Seibert et al, 1999). That's why, it is a need to check those variable that mediates the relation between proactive personality and performance. For example, it is the opinion by the researcher about those employees who gets higher job performance by using networking ability that is link with one construct of critical skill elaborated by (Thompson, 2005).

Apart from its impact, some of research studies have checked through models straightforwardly by which research found that proactive personality further enhance healthy relation on task-related results. Having in mind proactive personality is a personality trait, which is a good forecaster for behaviors related to the job of an employee, worked by (Barrick et al, 2002). Another researcher established that all those skills related to politics in organization create positive relation to task performance discussed by (Liu at el, 2007). To understand the mediation impact in a better way for four different types of skills of politics on performance, our research highlights the performance with reference to extra role and in role performance. In-role performance highlights the attitudes that particularly describe in the job of an employee and these attitudes directly link to the achievements of all those tasks which can add more worth for the organization. The contribution which made a value addition from performance of extra role enhances worth of the organization but it includes the attitudes 
whose intention is specifically on psyche, society and organization researched by (Motowidlo, 2003). So, these two roles of performances are equally essential for the organization.

As a researcher (Junqishi et al, 2010) has cited in his research which has been explored by (Katz, 1964) that it is necessary for a well performing organization their workers should keep on performing as particular description of the job and he himself also tries to perform above the description of job. Workers should add worth to the organization by giving them physical (e.g. material) unseen (e.g. encouragement, news, and time) and back up to the people in their assigned work, that is an element of altruism with reference to performance.

Most of the hypothetical mechanism related in literature, that include OCB, normally includes altruism as a significant part that is dimension of performance may be they differ particularly in other areas related to perform the behaviors for extra role discussed by (Motowidlo and Borman, 1993). Moreover, altruism has been examined for checking the impact of proactive approach in personality towards extra role performance. Through a procedural examination to see the mediate impact of different dimension among proactive approach in personality and required performance i.e. in-role performance and helping behavior weighted by participants' direct boss, our objective to give a more detailed perceptive about the models that tells us the useful impact of proactive personality on performance.

\section{Literature Review}

The existing study attempts to solve the short coming by examining different models of job performance. For the accomplishment of this goal we go through literature related to multi dimensional construct of political skills. This literature helps us in getting theoretical basis for the different hypotheses.

The main element of proactive personality is based on someone's social connection which derives that environment of the society is not only the factor which influence someone, persons connections does matter to influence others elaborated by (Bryan et al 2009). The skills of politics can be describe all those capabilities which help anyone to know about others with in the working environment and than utilize such understanding as knowledge to guide others according to in a direction which can help to achieve organizational or personal goals expressed by (Ahearn et al, 2004). Some of other researcher recognizes different dimensions of political skills like interpersonal influence, apparent sincerity, social astuteness and networking ability presented by (Ferris et al, 2005).

All those behavior which is demanded to perform by the fob description and normally those behaviors has greater link to achieve all those tasks which are necessary and more important to add some value for role of the organization is called in-roll performance. Literature has shown that the persons who uses proactively in their personalities are also good to perform according to the job description that is ultimately enhance the in role-performance. Researchers has explored that proactive personality is directly interlinked within role performance, which means that proactive person's in role performance lead to greater employee performance discussed by (Ashrod; Grant, 2008). To better understand proactive personality we have gone through from a reasonable literature related to altruism or extra role performance literature has gave many definitions about extra role behaviors many scholars and researchers has done work on the proactive personality and the importance of extra role behaviors or altruism.

Behaviors which are not specified in job description but employee or workmen himself or herself wanted to perform those behaviors, it includes every type of help which any worker or employee provide to his co worker or colleague to provide solution for the real time problems which his or her fellow facing during the performance of his or her job description worked by (Podsakoff, organ., 2000). But these behaviors just not be performed for the co worker or fellow in the organization one can help in the same manners to the stake holders of the organization i.e. public, customers dealers and people who have concerned whit purchases worked out by (Podsakoof et al, 2000). Performance of extra role behavior or altruism also highlights that, attitudes which are highly characterized by socialism and in the context of psychology discussed by (Motowidlo, 2003). To exemplify altruism behaviors researchers has established that, extra role behaviors or altruism can be perform by helping the trainees, new comers in performing their own task which has been described in their job description that help is important for their in role performance but by whom they are helped at that time for those it is altruism or extra roll performance at the same time researched by (Podsakoof et al, 2000).

To see the relation between of independent and dependent variables it is necessary to review political skills used in the organization to achieve performance and further more literature has helped by providing sufficient data on different construct of political skills, it includes networking ability interpersonal influence social astuteness and apparent sincerity. By getting all this appropriate literature review can help for better understanding the relationship of proactive personality within role performance and altruism or extra role performance that has 
already been discussed. Political skills involved factors which can leave an impact on people within someone social life and in the surroundings but this type of special skill is only a way to influence others just by understanding their mind sets to achieve personal goals. According to a researcher there are four main dimensions of political skills suited by (Ferris et al, 2005). These dimensions are discussed below:

The ability to make social network is one of the important mediating dimension for altruism in role performance. Researchers has established that the ability to make network and social contacts with respect to organizational as well as in society should be in a way that It can enhance overall performance in every task which is required to achieve, political skills which were encompasses by good networking skill is fruitful to achieve required individual as well as group performance discussed by (sparrow et al, 2001).Networking skills is strength to accurately recognize and to make a diverse type of connections and network with others. If an individual have extra skills related to network ability it should fruitful for people to gain good return from the prevailing situations while they are on a good designation and having worth able and important assets for their own and organizational growth.

Interpersonal influence can be said to personality style through which an individual induce others by adding energetic impact in their political skills to convince persons. Such type of interpersonal skill let people use to for handling different circumstances using their behaviors, which ultimately helps to get their goals. To make personally influenced to others like subordinates, superiors or follow co worker it is a marvelous additional quality which some individual hold through which they can easily make others motivate for achieving their goals discussed by (Ferris et al, 2005). "Interpersonal influence can be described as the capacity of an individual or a group (which may lie dormant) to exert their will over another or others" presented by (French and Raven, 2001).

As social astuteness is also most important dimension of using ability of politics to built an effective mediation relation between proactive personality and altruism or extra role performance and job in role behaviors, astuteness commonly can be said to observe persons and surroundings to analyze the prevailing circumstances for using those situations according to one's behavioral setting according to the need of running time in order to best utilization of those persons and environment for achieving one's goals were mentioned by (Ferris, et al 2007). Social astuteness seems to be a natural phenomenon of human's behavior and psyche in context of socialism, as it may be observed in daily life of organization as well society where everyone try to set his or her behavior and mind set according to the prevailing environment so that ultimately one can utilize his or her abilities in best manner for the set up goals.

Self monitoring is another important characteristics of people who use political skills in organizations for achieving high job performance people who themselves get into the processes of organizations are called high self monitors, people having proactive personality their political skills should be characterized by self monitoring because they normally do the work themselves instead depending on others mentioned by (K. Martin; David V, 1994). It has been seem that self monitoring individuals are mostly high achievers because due to their self monitoring on the processes they got maximum results and people in the organization as well as from society gave them high appreciation. This highly appreciated feed-back make them conscious about their public image and they always try to achieve high job performance which means that self monitoring pushes proactive personality towards altruism or helping behaviors and in role performance.

\section{Hypotheses Development and Theoretical Framework}

H1. Proactive personality has shown a significant positive relationship with in-role performance.

H2. Proactive personality has shown a significant positive relationship with Altruism.

H3. The interpersonal influence has shown significant positive mediation relationship between proactive personality and in-role performance.

H4. The social astuteness has shown a significant positive mediation relationship between proactive personality and in role performance and altruism.

H5. The networking ability has shown a significant positive relationship between proactive personality and in in-role performance and altruism.

H6. The self monitoring has shown a significant positive mediation relationship between proactive personality and in-role performance. 


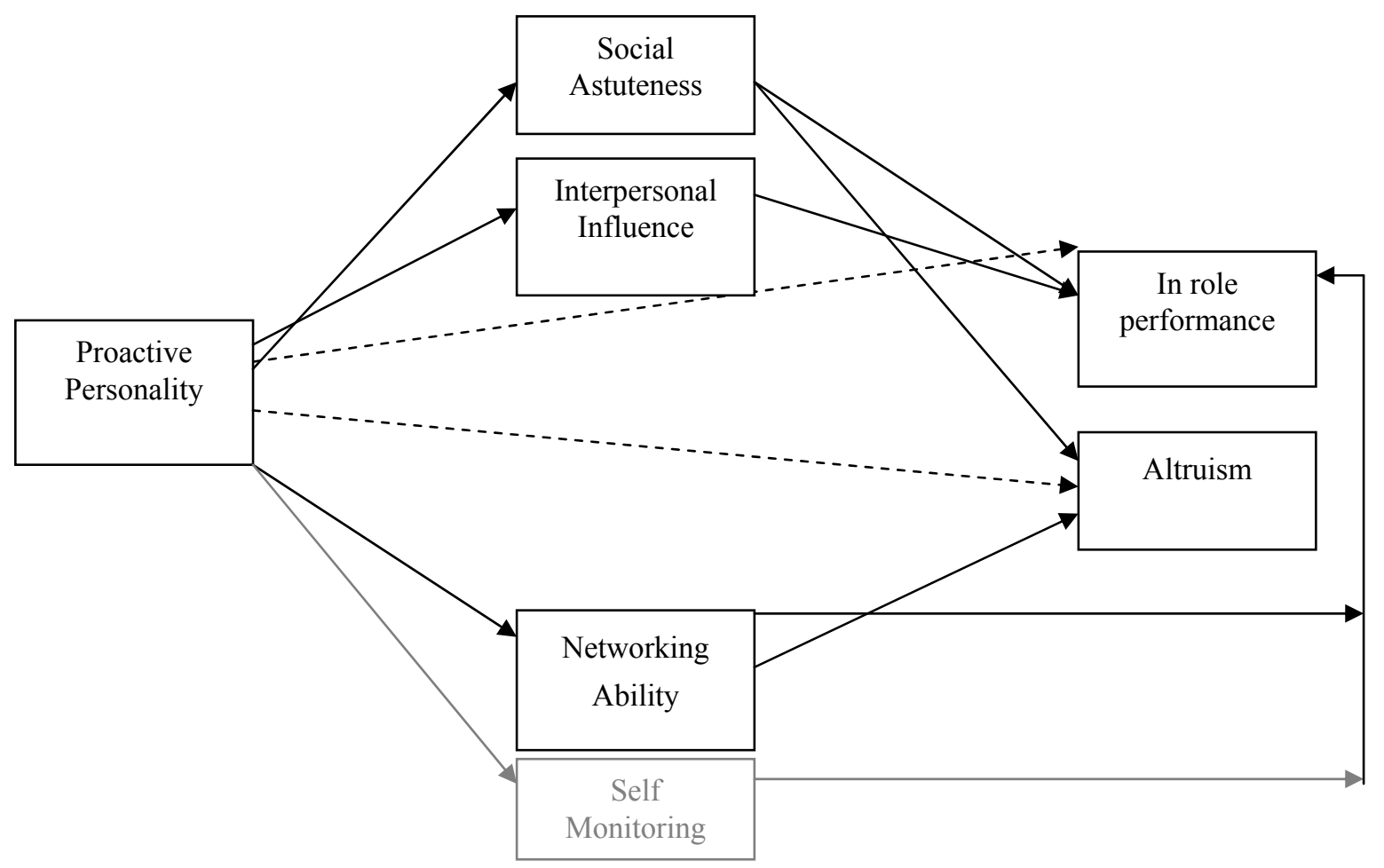

Figure 1. Theoretical model

\section{Methodology and Research Design}

Data will be collected from the major banks of Pakistan and Sample size will be of 400 employees. Random sampling method should be chosen for data collection form different rank of employees within those major banks, employees should be involved from top to functional level because every employee from different levels have its own tasks and concerns. Top level management routinely deals with policy making for the stakeholders, customers and employees of the organization while in this process they need to interact with all level of employees and on the other hand functional level employees usually get in touch with the customers, clients and parties as well as they interact with their colleagues or subordinate for solving the problems or for helping them. Resultantly their responses could be helpful to collect the appropriate data from the selected respondents through random sampling.

\section{Results and Discussion}

Although the existing literature has much data about employee performance with different dimensions some researchers just has done work on proactive personality and its relation to employee performance while literature has also highlight that many researcher has gone through different sub dimensions of political skills and its impact on employee performance. The recent literature has shown that different dimensions of political skills are taken to see the mediation impact of all those skills on proactive personality and in role performance and altruism directly or indirectly. Literature has explored that the mediation impact of social astuteness positively relates proactive personality to in role performance and altruism and proactive personality directly influenced on social astuteness as well as in role performance and altruism which consequently increase employee performance. Networking ability also stands as same as social astuteness is, proactive personality directly positively related within role and altruism while networking ability mediates positive relationship between proactive personality on dependent variables, due to networking ability one can easily pass through the important information to others as well he can also get help from others which automatically increase his or her performance on work. Interpersonal influence which is also an important skills of politics stands a bit different from others mediators in relation to proactive personality and in role performance and altruism although interpersonal influence mediates the relation between the proactive personality and in role performance in a positive way but it does not mediates proactive personality to altruism as interpersonal influence something which is related to use of power or authority on subordinates, and one can only use his or her authority on subordinates to influence them to perform according to the job description and requirement of the task but interpersonal influence cannot help to enhance helping 
behaviors or altruism in employees but consequently it will increase employee performance as mediates positively within role performance.

As per recommendation from the previous research work our study aims to see the mediation impact of self-monitoring with all other three mediators self-monitoring is although is a new mediator but it mediates positively proactive personality to in role performance only, as self-monitoring is conducted for the purpose of monitoring employees on job performance which consequently leads to high performance. Self-monitors are normally examines employees all those behaviors which are specifically related to their role in performance and self-monitors are normally can be found among leader of the teams or groups and they are highly characterized just on focusing their work even they are not much keep in contacts with their old colleagues mentioned by (Kilduff Martin,1994). Conflicts are normally occurs when an employee does not know what to perform i.e. job description in role performance and superior or boss also unable to get maximum performance form employee in this situation self-monitor persons can easily provide solutions because they were monitoring in to the organization their self and consequently in role performance should help to increase employee performance.

\section{Conclusion}

In concluding remarks our research envisages that all of the dimensions of political skills mediates positively between proactive personality and in role performance and altruism, our study also dig out a new insight by adding self-monitoring as a new mediator which increase the importance of political skills dimensions and the relation among proactive personality and dependent variables. The theoretical model shows the direct relationship of proactive personality and in role performance and altruism it envisages that the proactive personality and its relation with dependent variables is also important in increasing employee performance but the dimensions of political skills increase the affirmativeness of that relationship by mediating those dimensions on in role performance and extra role performance or altruism. The new exploration on previous study that is self-monitoring which can be play more effective role in increasing employee performance, but it could give some fruit only when self-monitoring take place practically in the organization by using three other dimensions of political skills for enhancing the employee performance, the future research may could bring modification in that model for making employee performance more effective.

This research has many managerial applications in the organizations to achieve maximum employee performance, if the theoretical modal implemented with full strength and then any organization can achieve results according to their prevailing environment. It is necessary to make the environment in the organization in a way that every employee can built himself or herself so that he or she can enhance their political skills which the leads to good performance. For the attainment of accurate results by the managerial application of the model the environment should be supportive for the employees to increase their network ability which effects altruism and in role performance, social astuteness should also effects accordingly while interpersonal influence and self monitoring will be more effective on in role performance only when the environment of the organization is supportive to implement the mechanism in which the relationship of proactive personality and job performance is exist, by providing the sufficient training to employees to enhancing the use of their political skills and its importance should also be helpful in getting the required results of the managerial application of this model that is to gain employee performance.

Recommendation for future research needs to test the model in other professional organizations, because our research limits within the banking sector of Pakistan and the population which is selected for sample only the employee's form banks. Although this model could be useful for any organization who wants to achieve employee performance by using political skill as mediators between proactive personality and in role performance and extra role performance or altruism but future study cannot explore new horizons only by changing organization for the testing of model. The most appropriate recommendation for future research is to examine dimension of political skills with respect to culture of the organization because culture has great impact on employee's performance.

\section{References}

Ashford, S. J., \& Grant, A. M. (2008). The dynamics of proactivity at work. Research in Organizational Behavior, 28, 3-34. http://dx.doi.org/10.1016/j.riob.2008.04.002

Barrick, M. R., Stewart, G. L., \& Piotrowski, M. (2002). Personality and job performance: Test of the mediating effects of motivation among sales representatives. Journal of Applied Psychology, 87, 43-51. http://dx.doi.org/10.1037/0021-9010.87.1.43

Borman, W. C., \& Motowidlo, S. J. (1997). The task performance \& Contextual performance: the meaning og 
perssonal selection Research. Human Performance, 10(2), 99-109. http://dx.doi.org/10.1207/s15327043hup1002_3

Bryan, A., Newman, W. R., \& Megan G. (2009). Understanding the impact of proactive personality on job performance: the roles of tenure and self-management. Journal of Leadership \& Organizational Studies, 16 (1), 61-72. http://dx.doi.org/10.1177/1548051809334192

Crant, M. J., \& Bateman, T. S. (2000). Charismatic leadership viewed from above: The impact of proactive $\begin{array}{llll}\text { personality. Journal of Organizational } & \text { Behavior, }\end{array}$ http://dx.doi.org/10.1002/(SICI)1099-1379(200002)21:1<63::AID-JOB8>3.0.CO;2-J

Ferris, G. R., Treadway, D. C., Kolodinsky, R. W., Hochwarter, W. A., Kacmar, C. J., \& Douglas, C., et al. (2005). Development and validation of the political skill inventory. Journal of Management, 31, 126-152. http://dx.doi.org/10.1177/0149206304271386

Ferris, G. R., Treadway, D. C., Perrewe', P. L., Brouer, R. L., Douglas, C., \& Lux, S. (2007). Political skill in organizations. Journal of Management, 33, 290-320. http://dx.doi.org/10.1177/0149206307300813

Junqi, S., Zhuo C., \& Zhou, L. (2010). Testing Differential Mediation Effects of Sub-dimensions of Political Skills in Linking Proactive Personality to Employee Performance. Journal of Business and Psychology. 26(3), 359-369.

Katz, D. (1964). Motivational basis of organizational behavior. Behavioral Science, 9, 131-146. http://dx.doi.org/10.1002/bs.3830090206

Kilduff, Martin \& David V. (1994). Do chameleons get ahead? The effects of self-monitoring on managerial careers. Academy of Management Journal, 37.

Motowidlo, S. J. (2003). Job performance. In W. C. Borman, D. R. Ilgen, \& R. J. Klimoski (Eds.), Handbook of psychology, 12, 39-53. http://dx.doi.org/10.1002/0471264385.wei1203

Podsakoff, P. M., MacKenzie, S. B., Paine, J. B., \& Bachrach, D. G. (2000). Organizational citizenship behaviors: A critical review of the theoretical and empirical literature and suggestions for future research. Journal of Management, 26, 13-563. http://dx.doi.org/10.1177/014920630002600307

Seibert, S. E., Crant, J. M., \& Kraimer, M. L. (1999). Proactive personality and career success. Journal of Applied Psychology, 84, 16-427. http://dx.doi.org/10.1037/0021-9010.84.3.416

Sparrowe, R. T., Liden, R. C., Wayne, S. J., \& Kraimer, M. L. (2001). Social networks and the performance of individuals and groups. Academy of Management Journal, 44, 316-325. http://dx.doi.org/10.2307/3069458 